\title{
Energy Efficiency Analysis of the Discharge Circuit of Caltech Spheromak Experiment
}

\author{
Deepak Kumar, Student Member, IEEE, Auna L. Moser, and Paul M. Bellan
}

\begin{abstract}
The Caltech spheromak experiment uses a size A ignitron in switching a $59-\mu \mathrm{F}$ capacitor bank (charged up to $8 \mathrm{kV}$ ) across an inductive plasma load. Typical power levels in the discharge circuit are $\sim 200 \mathrm{MW}$ for a duration of $\sim 10 \mu \mathrm{s}$. This paper describes the setup of the circuit and the measurements of various impedances in the circuit. The combined impedance of the size $A$ ignitron and the cables was found to be significantly larger than the plasma impedance. This causes the circuit to behave like a current source with low energy transfer efficiency. This behavior is expected to be common with other pulsed plasma experiments of similar size that employ an ignitron switch.
\end{abstract}

Index Terms-Energy efficiency, ignitron, inductance, spheromak.

\section{INTRODUCTION}

$\mathbf{T}$ HE EFFICIENCY of energy transfer from capacitor banks to a spheromak plasma is usually very low $(\lesssim 20 \%)$ [1]-[3]. This paper explains the observed energy efficiency of the discharge circuit of the Caltech spheromak experiment from a circuit analysis perspective. In particular, this paper describes the impedance measurements of the GL-7703 size A ignitron used in the Caltech spheromak experiment and its implications on the circuit behavior.

Ignitrons can switch a few Coulombs of charge on a fast time scale $(\sim 10 \mu \mathrm{s})$ [4]. They provide an affordable and robust switching technology, and so, they are used for many pulsed plasma experiments - spheromak formation [5], helicity injection [6], Z-pinch experiments [7], propulsion [8], etc. However, the high resistance $(\sim 25 \mathrm{~m} \Omega)$ and inductance $(\sim 50-200 \mathrm{nH})$ of the ignitron exceeds the plasma impedance and, hence, is often the main factor in determining circuit performance and efficiency.

Fig. 1 shows the schematic of the discharge circuit of the Caltech spheromak experiment [9], [10]. It consists of a highvoltage (HV) capacitor $(\sim 59 \mu \mathrm{F})$ switched by a GL-7703 size A ignitron [11]. As per specifications of the capacitor, the equivalent series inductance of the capacitor is $\lesssim 50 \mathrm{nH}$. The ignitron is connected to the discharge electrodes using four lowinductance coaxial cables (Belden YK-198) that are connected in parallel, with each cable about $3 \mathrm{~m}$ in length. The nominal inductance of each cable is $100 \mathrm{nH} / \mathrm{m}$ (as mentioned in the datasheet). Thus, the cables introduced a total inductance of

Manuscript received June 9, 2009; revised September 25, 2009. First published November 20, 2009; current version published January 7, 2010.

The authors are with the Applied Physics Department, California Institute of Technology, Pasadena, CA 91125 USA (e-mail: deeku@caltech.edu; auna@caltech.edu; pbellan@caltech.edu).

Color versions of one or more of the figures in this paper are available online at http://ieeexplore.ieee.org.

Digital Object Identifier 10.1109/TPS.2009.2034744

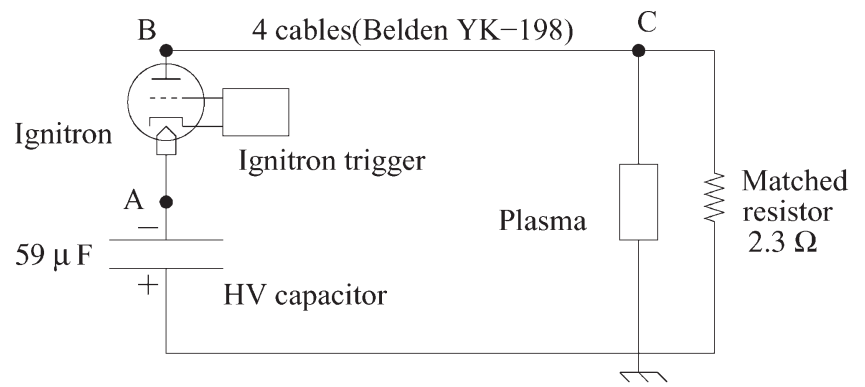

Fig. 1. Schematic of the spheromak discharge circuit.

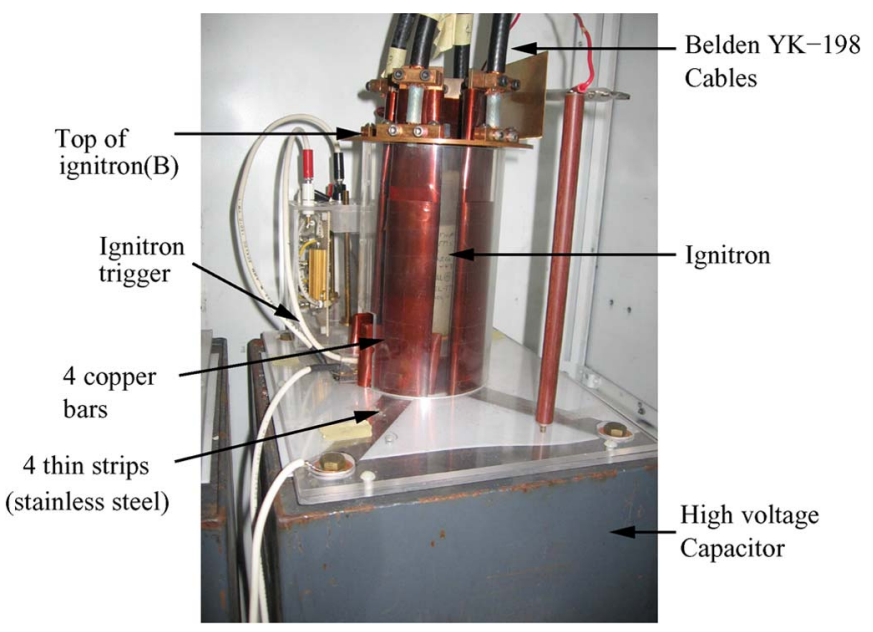

Fig. 2. Setup of the GL-7703 ignitron next to the HV capacitor.

$\sim 75 \mathrm{nH}$ in the discharge circuit. A resistor $(\sim 2.3 \Omega)$ matched to the characteristic impedance of the cables is connected across the electrodes. The matched resistor is made of three lowinductance tubular Carborundum resistors $(\sim 6.5 \Omega$ each) that are connected in parallel. It minimizes reflections of the initial voltage pulse before plasma breakdown. In the event that the plasma fails to ignite, the matched resistor also acts as a safety dump.

Fig. 2 shows the housing arrangement of the ignitron next to the HV capacitor. The top of the ignitron corresponds to point B in Fig. 1. The four copper bars are wrapped with insulating kapton tape and provide the return current path to the capacitor. The copper bars are placed extremely close to the ignitron to minimize stray inductance. Four stainless steel strips complete the return path of the current to the capacitor.

Plasma is created by a discharge across coplanar copper electrodes shown in Fig. 3. The inner cathode has a diameter of $20 \mathrm{~cm}$, and the outer annular anode has a diameter of $50 \mathrm{~cm}$. The cathode corresponds to point $\mathrm{C}$ in the schematic shown 


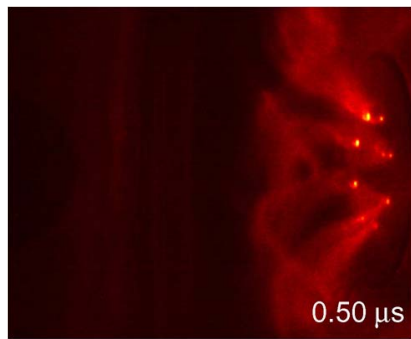

(a)

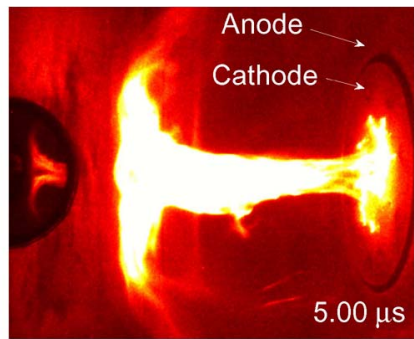

(b)
Fig. 3. Visual images of the two distinct stages of plasma evolution in the Caltech spheromak experiment. (a) Eight spider legs. (b) Collimated jet.

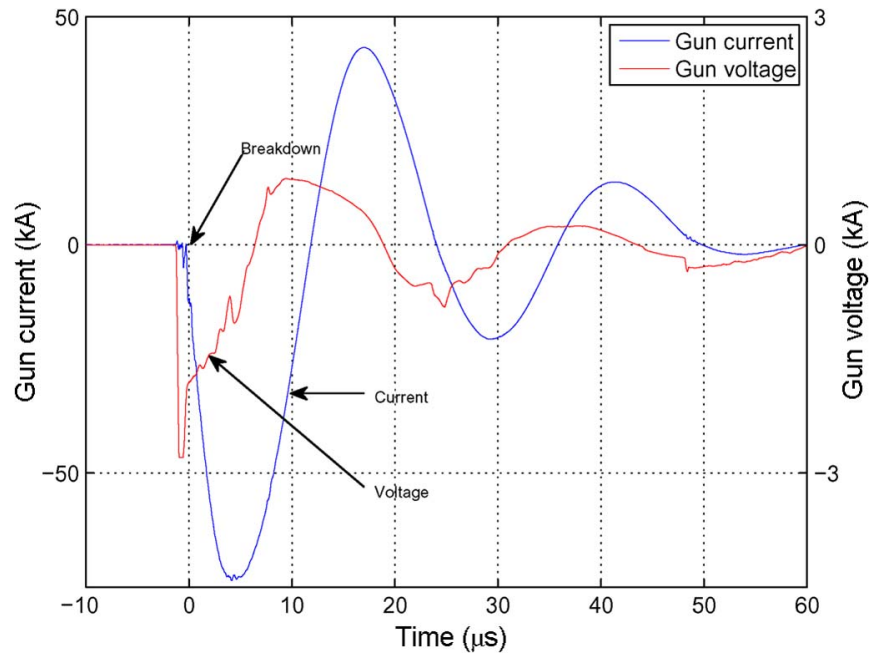

Fig. 4. Current and voltage traces measured across the electrodes for a typical plasma shot.

in Fig. 1, while the anode is grounded. A vacuum magnetic field created by a coil behind the electrodes links the inner disk cathode and outer annular anode. Just before the discharge, neutral gas is puffed near the electrodes using 16 orifices, with eight each on the two electrodes. Thus, at the breakdown, eight collimated plasma-filled flux tubes linking the electrodes along the gas orifices are formed in the experiment. These resemble eight legs of a spider, as shown in Fig. 3(a). As the eight flux tubes expand, they merge to form a collimated jet shown in Fig. 3(b). The stability of the jet against the kink mode is enhanced by increasing the strength of the applied vacuum magnetic field [9].

\section{RESULts}

\section{A. Plasma Parameters}

The plasma jet conducts current between the electrodes. As the jet expands, the inductance of the plasma increases. Typical current and voltage traces measured across the electrodes are shown in Fig. 4. Note that the traces are not in phase, implying that the plasma is inductive. The plasma experiments are conducted within the first half of the current oscillation (i.e., during the first $10 \mu$ s after breakdown). The voltage measured across the electrodes and the current flowing through the electrodes are related by

$$
V(t)=I(t)\left(R(t)+\frac{d L(t)}{d t}\right)+L(t) \frac{d I(t)}{d t}
$$

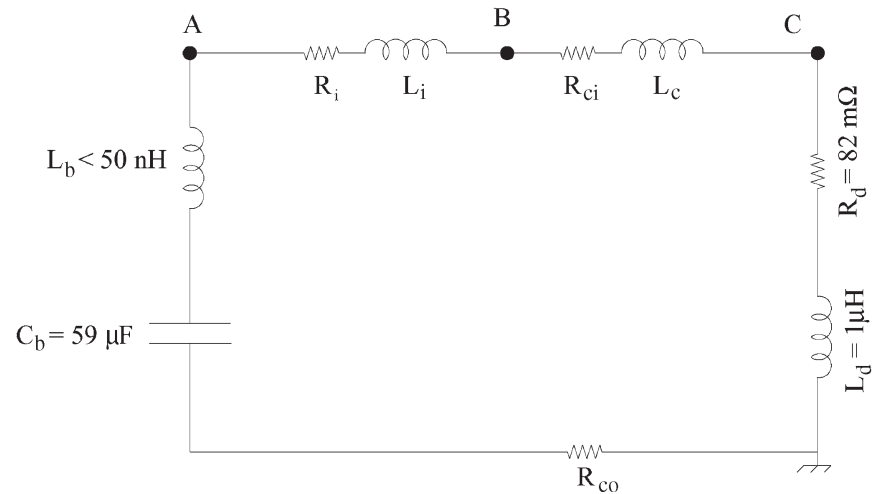

Fig. 5. Lumped circuit model for the discharge circuit across a dummy load.

where $V$ is the voltage measured across the electrodes, $I$ is the current flowing through the electrodes and the plasma, $L$ is the time-varying inductance of the plasma structure, and $R$ is the time-varying resistance of the plasma. At breakdown, plasma inductance can be estimated as $L \sim V / \dot{I} \sim 50 \mathrm{nH}$. Similar arguments have been used to estimate plasma inductances in other spheromak experiments [12], [13]. Equation (1) implies that $(R+\dot{L}) \sim V / I$ when $I(t)$ is at a local extrema. Thus, the sum of the plasma resistance and the rate of change of inductance can be estimated from Fig. 4 to be $(R+\dot{L}) \sim$ $V / I \sim 12 \mathrm{~m} \Omega$ when $I(t)$ is at its minimum at $t \sim 4.3 \mu \mathrm{s}$.

The plasma jets produced in the experiment conduct current up to an inner radius of $r_{\circ} \sim 10 \mathrm{~cm}^{1}$ and have an outer return current at radius $r \sim 25 \mathrm{~cm}$, a length of $l \sim 20 \mathrm{~cm}$, and outward velocity of $v \sim 30 \mathrm{~km} / \mathrm{s}$ [14]. Thus, the inductance and the rate of change of inductance in these jets can be approximated as

$$
\begin{aligned}
& L \sim \frac{\mu_{\circ} l}{2 \pi} \log \left(\frac{r}{r_{\circ}}\right) \sim 35 \mathrm{nH} \\
& \dot{L} \sim \frac{\mu_{\circ} v}{2 \pi} \log \left(\frac{r}{r_{\circ}}\right) \sim 5.5 \mathrm{~m} \Omega .
\end{aligned}
$$

The resistance of the plasma jet can also be estimated by similar geometric considerations. The plasma ion temperature $T_{i}$ is $\sim 2 \mathrm{eV}$ [15, Pg. 53]. Since the plasma is extremely collisional [14], the plasma electron temperature $T_{e}$ should be equal to the ion temperature $T_{i}$. This implies a Spitzer resistivity of $\eta \sim 3.6 \times 10^{-4} \Omega \mathrm{m}$. Thus, plasma resistance can be estimated as $R \sim \eta l / \pi r_{\circ}^{2} \sim 2.5 \mathrm{~m} \Omega$. Due to the uncertainties involved with the Coulomb logarithm and the plasma geometry, this is a rough estimate of plasma resistance. However, it shows that plasma resistance and its rate of change of inductance are comparable to each other.

\section{B. Other Circuit Parameters}

In order to measure the impedances of the cables and the ignitron, the plasma and the matched resistor were replaced by a fixed dummy load of resistance $82 \mathrm{~m} \Omega$ and inductance $1 \mu \mathrm{H}$. A lumped circuit model for the setup is shown in Fig. 5. $R_{c i}$ represents the resistance of the inner conductor of the cables.

\footnotetext{
${ }^{1}$ The radius of the current channel $\left(r_{\circ} \sim 10 \mathrm{~cm}\right)$ is much greater than the radius of the plasma jet $(\sim 3 \mathrm{~cm})$ inferred from visible images [see Fig. 3(b)].
} 


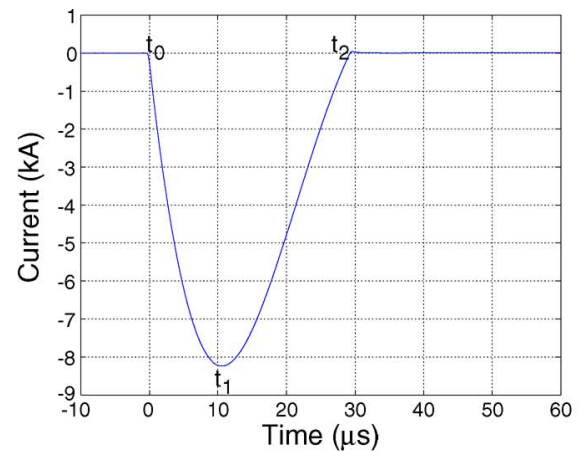

(a)

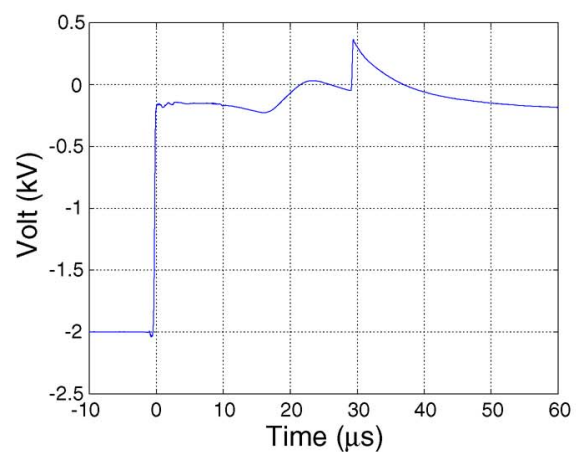

(b)

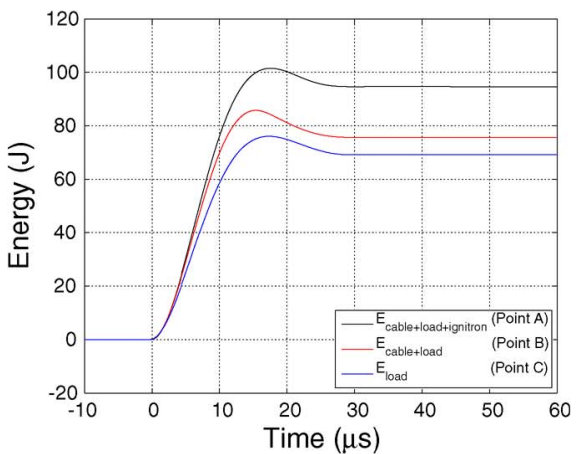

(c)

Fig. 6. Measurements from discharging the HV capacitor charged to $2 \mathrm{kV}$ across the dummy load. (a) Current flowing through the dummy load. (b) Voltage across the ignitron $\left(V_{A}-V_{B}\right)$ (see Fig. 5). (c) Energy $E=\int_{0}^{t} V I d t$ flowing into the dummy load, where the current $I$ is shown in Fig. 6(a) and the voltage $V$ was measured at points A, B, and C (see Fig. 5).

$R_{c o}$ represents the resistance in the current return path and is the sum of the resistance of the outer conductor of the cables and the resistance of the four stainless steel strips shown in Fig. 2. $L_{c}$ and $L_{b}$ represent the equivalent series inductance of the cables and the capacitor bank, respectively $\left(L_{c} \sim 75 \mathrm{nH}\right.$ and $\left.L_{b} \lesssim 50 \mathrm{nH}\right) . R_{i}\left(R_{d}\right)$ and $L_{i}\left(L_{d}\right)$ represent the resistance and inductance of the ignitron (dummy load), respectively. A series of shots was done by charging the HV capacitor to $2 \mathrm{kV}$ and discharging it across the dummy load. Voltages were measured at points "A," "B," and "C" in the circuit (see Fig. 5). The current flowing through the circuit and the voltage measured at these points can be used to calculate the net energy flow across these points from the time integral of the Poynting flux $E_{X}=\int_{0}^{\infty} V_{X}(t) I(t) d t$, where $\mathrm{X}$ is "A," "B," or "C."

As $t \rightarrow \infty$, the current in the circuit $I(t) \rightarrow 0$. Thus, as $t \rightarrow$ $\infty$, the entire energy $E_{X}$ is dissipated resistively. This implies

$$
E_{X}=\int_{0}^{\infty} V_{X}(t) I(t) d t=\int_{0}^{\infty} R_{X}(t) I^{2}(t) d t
$$

where $R_{X}(t)$ is the resistance between the point " $\mathrm{X}$ " and the circuit ground. An estimate of the resistance $R_{X}$ can thus be obtained by

$$
R_{X} \sim \frac{E_{X}}{\int_{0}^{\infty} I^{2}(t) d t} .
$$

Equation (2) is used repeatedly in this paper to estimate the various resistances in the discharge circuit.

The total energy dissipated across the cable inner conductor and the load (see Fig. 6) is $E_{\text {inner+load }}=\int_{0}^{\infty} I^{2}\left(R_{c i}+\right.$ $\left.R_{d}\right) d t$. Since the energy dissipated across the load is $E_{\text {load }}=\int_{0}^{\infty} I^{2} R_{d} d t$, we measure from the experiments that $\quad R_{c i}=R_{d}\left[\left(E_{\text {inner+load }}-E_{\text {load }}\right) / E_{\text {load }}\right]=R_{d}\left[\left(E_{\mathrm{B}}-\right.\right.$ $\left.\left.E_{\mathrm{C}}\right) / E_{\mathrm{C}}\right] \sim 8 \mathrm{~m} \Omega$.

The initial capacitor bank energy is $E_{\text {capacitor }} \sim 115 \mathrm{~J}$. Part of it is dissipated across the resistance $R_{c o}$ in the current's return path. Thus, $R_{c o} \sim R_{d}\left[\left(E_{\text {capacitor }}-\right.\right.$ $\left.\left.E_{\text {inner+load+ignitron }}\right) / E_{\text {load }}\right] \sim 23 \mathrm{~m} \Omega$. The resistance $R_{c o}$ is the cumulative effect of the resistance of the stainless steel strips shown in Fig. 2 (measured to be $\sim 13 \mathrm{~m} \Omega$ ) and the resistance of the outer conductor of the Belden YK-198 cables.
TABLE I

MEASUREd IMPEdANCE OF IGNITRON GL-7703

\begin{tabular}{|c|c|c|}
\hline Regime & Parameter & Estimate \\
\hline \multirow{2}{*}{ Low current $(\sim 10 \mathrm{kA})$} & $L_{i}$ - Inductance & $\begin{array}{c}170 \mathrm{nH} \text { (typical), } \\
800 \mathrm{nH} \text { (at ignitron turnoff) }\end{array}$ \\
\cline { 2 - 3 } & $R_{i}$ - Resistance & $22 \mathrm{~m} \Omega$ \\
\hline \multirow{2}{*}{ High current $(\sim 80 \mathrm{kA})$} & $L_{i}$ - Inductance & $50 \mathrm{nH}$ \\
\cline { 2 - 3 } & $R_{i}$ - Resistance & $29 \mathrm{~m} \Omega$ \\
\hline
\end{tabular}

The ignitron resistance is expected to be time and load dependent, but an average value can be estimated as $R_{i} \sim$ $R_{d}\left[\left(E_{\text {inner+load+ignitron }}-E_{\text {load }}\right) / E_{\text {load }}\right]-R_{c i}=R_{d}\left[\left(E_{\mathrm{A}}-\right.\right.$ $\left.\left.E_{\mathrm{C}}\right) / E_{\mathrm{C}}\right]-R_{c i} \sim 22 \mathrm{~m} \Omega$. The ignitron resistance may also be estimated by $R_{i} \sim\left(V_{\text {ignitron }} / I_{\text {ignitron }}\right)$, evaluated at time $t_{1}$ from Fig. 6(a) and (b). This leads to an estimate of $R_{i} \sim 21 \mathrm{~m} \Omega$.

An average value of the ignitron inductance can be estimated by $L_{i} \sim\left(V_{\text {ignitron }} / \dot{I}_{\text {ignitron }}\right)$, when $I_{\text {ignitron }} \sim 0$. From Fig. 6(a), $L_{i} \sim 170 \mathrm{nH}$ at time $t_{0}$. Also, from Fig. 6(a), $L_{i} \sim 800 \mathrm{nH}$ at the turnoff time $t_{2}$, when the ignitron stops conducting.

The ignitron resistance and inductance estimated earlier is expected to depend on the current flowing through the ignitron. Thus, a series of shots was done by charging the HV capacitor to $7 \mathrm{kV}$ and discharging it across the electrodes to create a plasma. As shown in Fig. 4, the typical current through the ignitron in such shots is $\sim 80 \mathrm{kA}$. Voltage was measured at both ends of the ignitron. By a similar analysis as described for the dummy load shots, the ignitron resistance was estimated from the fraction of capacitor bank energy dissipated across the ignitron. It yielded an estimate of $R_{i} \sim 29 \mathrm{~m} \Omega$. The ignitron inductance was estimated by $L_{i} \sim\left(V_{\text {ignitron }} / \dot{I}_{\text {ignitron }}\right)$, when $I_{\text {ignitron }} \sim 0$, and yielded $L_{i} \sim 50 \mathrm{nH}$.

\section{Summary of Results}

Table I lists the characteristic impedances of the ignitron GL-7703. For the low current case, the ignitron inductance was found to be much higher than the nominal value of $20 \mathrm{nH}$ mentioned in the datasheet [11]. Also, the ignitron resistance 
TABLE II

Typical Parameters of the Discharge Circuit of the Caltech SPHEROMAK EXPERIMENT (HIGH CURRENT $\sim 80 \mathrm{kA}$ )

\begin{tabular}{|c|c|}
\hline Parameter & $\begin{array}{l}\text { Approximate } \\
\text { estimate }\end{array}$ \\
\hline $\begin{array}{c}R_{p} \\
\text { plasma resistance }\end{array}$ & $2.5 \mathrm{~m} \Omega^{\mathrm{OM}}$ (Spitzer) \\
\hline $\begin{array}{c}L_{p} \\
\text { plasma inductance }\end{array}$ & $\begin{array}{c}30 \mathrm{nH}^{\mathrm{GC}} \text { (typical), } \\
50 \mathrm{nH}^{\mathrm{MT}} \text { (at breakdown) }\end{array}$ \\
\hline $\begin{array}{c}\omega_{d} L_{p} \\
\text { plasma inductive impedance }\end{array}$ & $8-13 \mathrm{~m} \Omega$ \\
\hline $\begin{array}{c}\dot{L}_{p} \\
\text { rate of change of plasma inductance }\end{array}$ & $6 \mathrm{~m} \Omega^{\mathrm{GC}}$ \\
\hline $\begin{array}{c}R_{c i} \\
\text { cable resistance - inner conductor }\end{array}$ & $8 \mathrm{~m} \Omega^{\mathrm{MT}}$ \\
\hline $\begin{array}{c}R_{c o} \\
\text { resistance in current return path }\end{array}$ & $23 \mathrm{~m} \Omega^{\mathrm{MT}}$ \\
\hline $\begin{array}{c}R_{i} \\
\text { ignitron resistance }\end{array}$ & $29 \mathrm{~m} \Omega^{\mathrm{MT}}$ \\
\hline $\begin{array}{l}\qquad R=R_{i}+R_{c o}+R_{c i}+R_{p} \\
\text { total series resistance in discharge circuit }\end{array}$ & $63 \mathrm{~m} \Omega$ \\
\hline $\begin{array}{c}L_{i} \\
\text { ignitron inductance }\end{array}$ & $50 \mathrm{nH}^{\mathrm{MT}}$ \\
\hline $\begin{array}{c}L_{b} \\
\text { equivalent series inductance of capacitor }\end{array}$ & $50 \mathrm{nH}^{\mathrm{DS}}$ (maximum) \\
\hline $\begin{array}{c}L_{c} \\
\text { inductance of cables }\end{array}$ & $75 \mathrm{nH}^{\mathrm{DS}}$ \\
\hline $\begin{array}{l}\qquad L=L_{b}+L_{i}+L_{c}+L_{p} \\
\text { total series inductance in discharge circuit }\end{array}$ & $215 \mathrm{nH}$ \\
\hline
\end{tabular}

was found to be high $(\sim 25 \mathrm{~m} \Omega)$ and relatively independent of the current flowing through the ignitron. Similar estimate for ignitron resistance has been reported earlier [16]. Note that the ignitron resistance is expected to be high $(\sim 20 \mathrm{~m} \Omega)$ for current pulses with smaller time scales $(\sim 10 \mu \mathrm{s})$ and substantially lower $(\sim 5 \mathrm{~m} \Omega)$ for current pulses with longer time scales

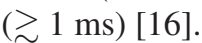

The damped frequency of oscillations in the current trace from a typical spheromak plasma shot (see Fig. 4) is $\omega_{d} \sim$ $2.7 \times 10^{5} \mathrm{rad} / \mathrm{s}$. Thus, the various impedances in the spheromak discharge circuit are summarized in Table II. The superscript in the second column indicates if the quantity is an order of magnitude estimate $(\mathrm{OM})$, an estimate from geometrical considerations (GC), measured from current/voltage traces (MT), or calculated from the datasheet (DS).

\section{CONCLUSION}

The estimates from Tables I and II can be used to draw the following conclusions.

1) Low energy coupling efficiency: Since the total resistance in the discharge circuit substantially exceeds the resistance of the plasma, the energy coupling efficiency of the circuit is low. Fig. 7 shows the time integral of the Poynting flux into the plasma (and the corresponding efficiency $\sim 24 \%$ ) for a typical plasma discharge. A low energy coupling efficiency has been observed in other experiments involving ignitrons as well [17]. Note that, with higher plasma temperature, the resistance of the plasma is expected to decrease, thereby causing a further decrease in the efficiency. An energy coupling efficiency of $\sim 60 \%$ has been reported previously, even while using ignitrons [18]. However, that was because, for a longer

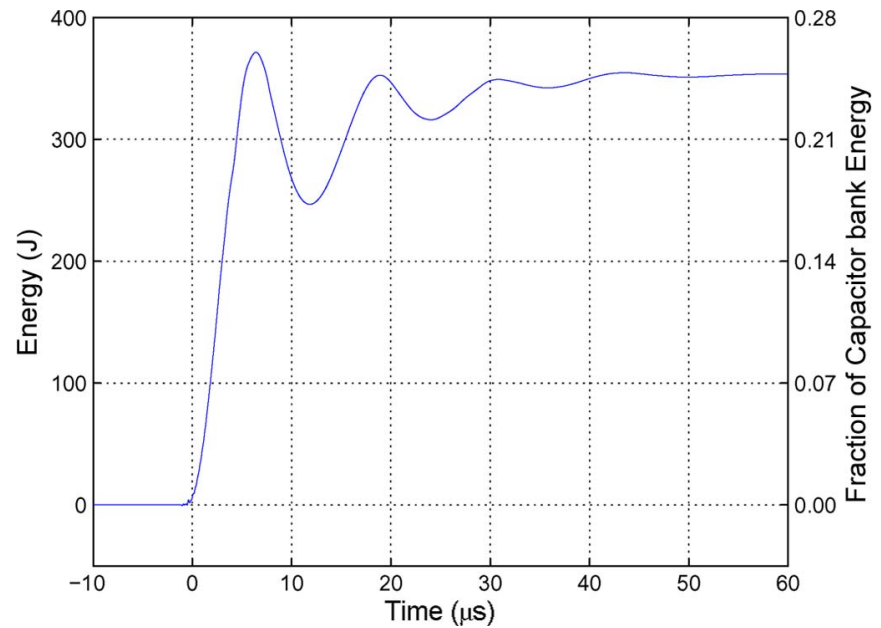

Fig. 7. Energy $\left(=\int_{0}^{t} V I d t\right)$ flowing into the plasma. A $59-\mu \mathrm{F}$ capacitor charged to $7 \mathrm{kV}$ was discharged into a deuterium plasma. Total capacitor bank energy $\approx 1500 \mathrm{~J}$.

pulse duration ( $\sim 3 \mathrm{~ms}$ ), the external (ignitron) resistance ( $3 \mathrm{~m} \Omega$ ) was much smaller and, hence, comparable to the plasma resistance $(2 \mathrm{~m} \Omega)$. The resistance of the switch in a pulsed power circuit has an adverse effect on the energy coupling efficiency. Thus, using spark gaps, which have low resistance $(\sim 1 \mathrm{~m} \Omega)$, may lead to even higher efficiencies ( 90\%) [19].

2) Underdamped discharge circuit: For the typical parameters shown in Table II, the discharge circuit is underdamped, with the frequency of these damped oscillations $\omega_{d}=\sqrt{(1 / L C)\left(1-\zeta^{2}\right)}$, where the damping factor $\zeta=(R / 2) \sqrt{C / L}$. Using nominal values of $C=59 \mu \mathrm{F}$, $L=215 \mathrm{nH}$, and $R=63 \mathrm{~m} \Omega$, we get $\zeta \sim 0.5$, and $\omega_{d}=2.4 \times 10^{5} \mathrm{rad} / \mathrm{s}$, which is very close to the observed frequency of oscillations in Fig. 4.

3) Discharge circuit is a current source: Table II shows that the combined impedance of the ignitron and the cables dominates the impedance of the plasma. Thus, plasma impedance plays a negligible role in determining the temporal profile of the current trace in the circuit. Fig. 8(d) shows that the frequency of the damped oscillations remains close to $2.7 \times 10^{5} \mathrm{rad} / \mathrm{s}$ by changing the following: a) the discharge voltage of the capacitor bank [see Fig. 8(a)]; b) the poloidal bias flux in the experiment [see Fig. 8(b)]; c) the neutral gas species [see Fig. 8(c)]; and d) the number of capacitors in the discharge circuit [see Fig. 8(d)]. With two capacitors being discharged across the plasma, the temporal behavior of the current trace did not change significantly because, even though the capacitance in the circuit increased twofold, the resistance and the inductance also increased almost twofold due to the extra ignitron and the cables (see Fig. 9). Thus, the Caltech spheromak discharge circuit acts as a current source driving an inductive plasma load.

4) High ignitron inductance: The GL-7703 is a commercially available low-inductance ignitron. The product datasheet [11] lists its approximate inductance to be $20 \mathrm{nH}$. The inductance measurements of other ignitrons have revealed both very low $(\sim 10 \mathrm{nH})$ [20] and 


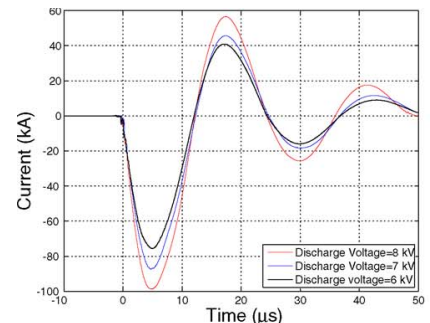

(a)

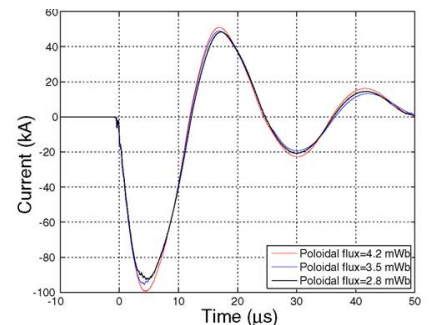

(b)

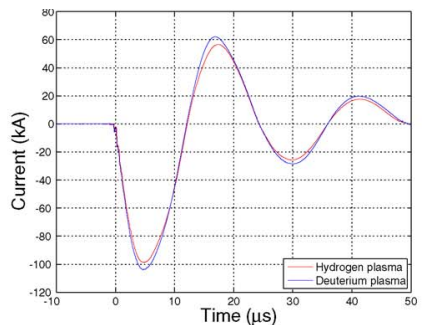

(c)

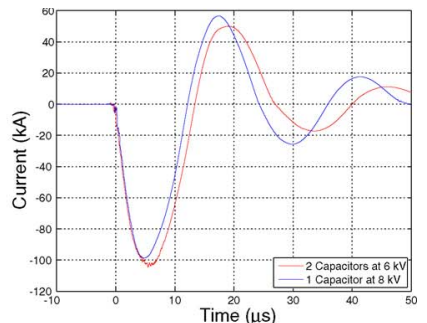

(d)

Fig. 8. Current trace from various plasma shots showing that the temporal behavior of the current trace did not change significantly by varying the parameters.

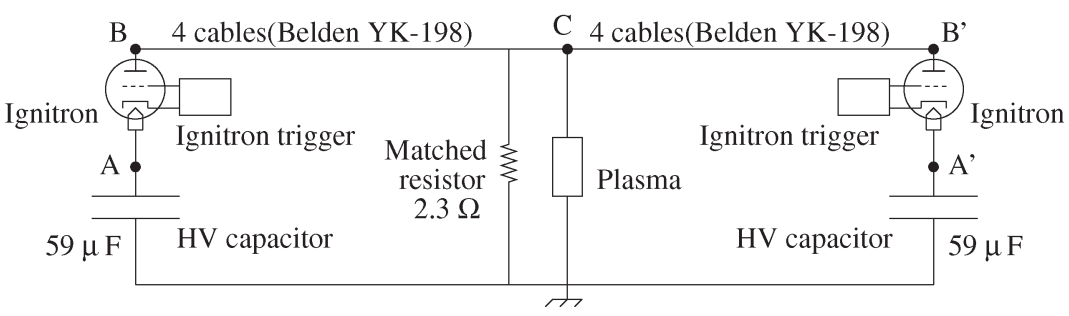

Fig. 9. Schematic of the spheromak discharge circuit using two HV capacitors.

sometimes higher estimates $(\sim 200 \mathrm{nH})$ as well [16]. Our analysis estimates the inductance to be high (170$800 \mathrm{nH})$ for low current regime and low $(50 \mathrm{nH})$ for higher current.

\section{ACKNOWLEDGMENT}

The authors would like to thank F. Cosso, M. Brown, S. Hsu, D. Felt, and S. You for building and maintaining the Caltech spheromak discharge circuit.

\section{REFERENCES}

[1] C. W. Barnes, T. R. Jarboe, G. J. Marklin, S. O. Knox, and I. Henins, "The impedance and energy efficiency of a coaxial magnetized plasma source used for spheromak formation and sustainment," Phys. Fluids B, Plasma Phys., vol. 2, no. 8, pp. 1871-1888, Aug. 1990.

[2] M. Brown and P. Bellan, "Efficiency and scaling of current drive and refuelling by spheromak injection into a tokamak," Nucl. Fus., vol. 32, no. 7, pp. 1125-1137, Jul. 1992.

[3] S. Woodruff, "Technical survey of simply connected compact tori (CTs): Spheromaks, FRCs and compression schemes," J. Fusion Energy, vol. 27, no. 1/2, pp. 134-148, Jun. 2008.

[4] W. J. Sarjeant and R. E. Dollinger, High-Power Electronics. New York: TAB, 1989, ch. 7, pp. 231-237.

[5] H. S. McLean, A. Ahmed, D. Buchenauer, D. D. Hartog, C. W. Domier, D. N. Hill, C. Holcomb, E. B. Hooper, E. C. Morse, M. Nagata, Y. Roh, B. Stallard, R. D. Wood, S. Woodruff, G. Wurden, and Z. Wang, "Plasma diagnostics for the sustained spheromak physics experiment," Rev. Sci. Instrum., vol. 72, no. 1, pp. 556-561, Jan. 2001.

[6] R. Raman, D. Mueller, T. Jarboe, B. Nelson, M. Bell, M. Ono, T. Bigelow, R. Kaita, B. LeBlanc, K. Lee, R. Maqueda, J. Menard, S. Paul, and L. Roquemore, "Non-inductive solenoid-less plasma current startup in NSTX using transient CHI," Nucl. Fus., vol. 47, no. 8, pp. 792-799, Jul. 2007.

[7] R. P. Golingo, U. Shumlak, and B. A. Nelson, "Formation of a sheared flow Z pinch," Phys. Plasmas, vol. 12, no. 6, p. 062 505, Jun. 2005.

[8] F. Paganucci, M. Zuin, M. Agostini, M. Andrenucci, V. Antoni, M. Bagatin, F. Bonomo, R. Cavazzana, P. Franz, L. Marrelli, P. Martin, E. Martines, P. Rossetti, G. Serianni, P. Scarin, M. Signori, and G. Spizzo, "MHD instabilities in magneto-plasma-dynamic thrusters," Plasma Phys. Control. Fusion, vol. 50, no. 12, p. 124 010, Dec. 2008.

[9] S. C. Hsu and P. M. Bellan, "Experimental identification of the kink instability as a poloidal flux amplification mechanism for coaxial gun spheromak formation," Phys. Rev. Lett., vol. 90, no. 21, p. 215002 , May 2003
[10] S. You, G. S. Yun, and P. M. Bellan, "Dynamic and stagnating plasma flow leading to magnetic-flux-tube collimation," Phys. Rev. Lett., vol. 95, no. 4, p. 045 002, Jul. 2005.

[11] GL-7703 Product Information, Mar. 2009. [Online]. Available: http:// catalog.rell.com/rellecom/Images/Objects/8200/8103.PDF

[12] B. W. Stallard, E. B. Hooper, S. Woodruff, R. H. Bulmer, D. N. Hill, H. S. McLean, and R. D. Wood, "Magnetic helicity balance in the sustained spheromak plasma experiment," Phys. Plasmas, vol. 10, no. 7, pp. 2912-2924, Jul. 2003.

[13] S. Woodruff, B. I. Cohen, E. B. Hooper, H. S. Mclean, B. W. Stallard, D. N. Hill, C. T. Holcomb, C. Romero-Talamas, R. D. Wood, G. Cone, and C. R. Sovinec, "Controlled and spontaneous magnetic field generation in a gun-driven spheromak," Phys. Plasmas, vol. 12, no. 5, p. 052502 , May 2005.

[14] D. Kumar, "Experimental investigations of magnetohydrodynamic plasma jets," Ph.D. dissertation, California Inst. Technol., Pasadena, CA, Mar. 2009.

[15] G. S. Yun, "Dynamics of plasma structures interacting with external and self-generated magnetic fields," Ph.D. dissertation, California Inst. Technol., Pasadena, CA, Jul. 2007.

[16] L. W. Kerr, J. W. McConkey, and J. W. G. Wilson, "The BK24 ignitron as a high current switch," Int. J. Electron., vol. 14, no. 2, pp. 223-230, Feb. 1963.

[17] C. J. Michels and F. F. Terdan, "Characteristics of a 5-kilojoule, ignitronswitched, fast-capacitor bank," Lewis Res. Center, Cleveland, OH, 1965.

[18] Z. Wang, P. D. Beinke, C. W. Barnes, M. W. Martin, E. Mignardot, G. A. Wurden, S. C. Hsu, T. P. Intrator, and C. P. Munson, "A Penningassisted subkilovolt coaxial plasma source," Rev. Sci. Instrum., vol. 76, no. 3, p. 033 501, Mar. 2005.

[19] M. Savage, "Final results from the high-current, high-action closing switch test program at Sandia National Laboratories," IEEE Trans. Plasma Sci., vol. 28, no. 5, pp. 1451-1455, Oct. 2000.

[20] D. B. Cummings, "A stabilized switching ignitron," IEEE Trans. Nucl. Sci., vol. NS-11, no. 1, pp. 345-350, Jan. 1964.

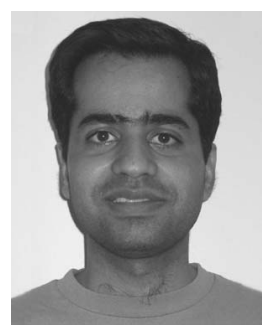

Deepak Kumar (S'04) received the B. Tech. degree in electrical engineering from Indian Institute of Technology, Mumbai, India, in 2001, the M.S. degree in electrical engineering from Texas A\&M University, College Station, in 2003, and the M.S. degree in applied physics and the Ph.D. degree from California Institute of Technology, Pasadena, in 2004 and 2009, respectively.

His research interests include plasma confinement, spheromak formation, plasma diagnostics, and pulsed power

Dr. Kumar is a Student Member of American Physical Society. 


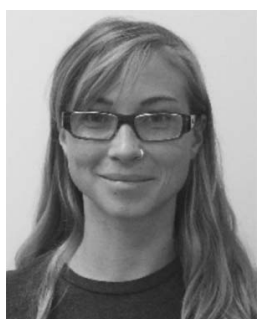

Auna L. Moser received the B.S. degree from California Institute of Technology (Caltech), Pasadena, in 2002. She is currently working toward the Ph.D. degree in the Caltech plasma physics research group.

She was a laboratory assistant from 2002 until 2004, when she enrolled as a graduate student in applied physics at Caltech. Her research interests include spheromak formation, laboratory astrophysics, and critical ionization velocity effects in laboratory plasmas.

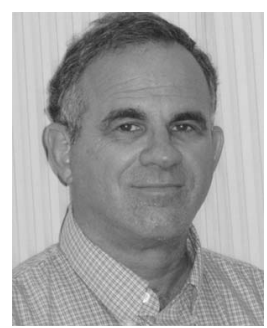

Paul M. Bellan received the B.Sc.(Hon.) degree from the University of Manitoba, Winnipeg, MB Canada, in 1970 and the M.A. and Ph.D. degrees in plasma physics from Princeton University, Princeton, NJ, in 1972 and 1975, respectively.

After holding a postdoctoral position with the Princeton Plasma Physics Laboratory, he joined the faculty of California Institute of Technology, Pasadena, in 1977, where he is currently a Professor of applied physics. His research activities include experimental and theoretical studies of lower hybrid wave propagation in plasmas, drift Alfvén waves, laser-induced fluorescence of plasmas, stochastic ion heating by coherent drift waves, magnetic helicity injection into tokamaks, spheromak injection into tokamaks, RF current drive in tokamaks, stability of arcs, astrophysical jets, and solar coronal loops. He is the author of over 100 scientific publications and two books.

Dr. Bellan is a Fellow of the American Physical Society. 